\title{
Kemampuan Membedakan Kalimat Majemuk Setara dan Kalimat Majemuk Bertingkat Bahasa Indonesia Siswa Kelas Xc SMA Negeri 7 Manado
}

\author{
Megalita Smarty Mandang \\ Jurusan Pendidikan Bahasa dan Sastra Indonesia, Fakultas Bahasa dan Seni Universitas Negeri \\ Manado
}

mandangmega@gmail.com

\begin{abstract}
Abstrak. Tujuan penelitian ini adalah untuk mengetahui kemampuan membedakan kalimat majemuk setara dan kalimat majemuk bertingkat bahasa Indonesia siswa kelas Xc SMA Negeri 7 Manado. Metode yang digunakan dalam penelitian ini yaitu metode deskriptif kualitatif. Metode deskriptif kualitatif adalah metode yang memusatkan diri pada masalah-masalah yang aktual. Data yang dikumpulkan mula-mula disusun, diperiksa kemudian dianalisis. Teknik pengumpulan data yang digunakan dalam penelitian ini adalah observasi, wawancara dan tes, sedangkan teknik yang digunakan untuk menganalisis data penelitian adalah menggunakan data tabel persentase dengan mengacu pada rumus yang dikemukakan Ali. Sumber data dalam penelitian ini adalah siswa kelas Xc SMA Negeri 7 Manado yang berjumlah 40 orang siswa. Data kemampuan siswa diperoleh dengan cara memberi tes berupa 20 buah kalimat yang diacak, terdiri dari 10 buah kalimat majemuk setara dan 10 buah kalimat majemuk bertingkat, serta tes menyusun kalimat majemuk setara maupun kalimat majemuk bertingkat dengan katakata yang tersedia masing-masing sebanyak 10 buah. Jadi seluruhnya berjumlah 40 buah kalimat dengan bobot 2,5. Berdasarkan hasil yang diperoleh, disimpulkan bahwa kemampuan membedakan kalimat majemuk setara dan kalimat majemuk bertingkat bahasa Indonesia siswa kelas Xc SMA Negeri 7 Manado adalah 70,15\% yang berada pada rentang nilai $70 \%-79 \%$ dengan kategori cukup.
\end{abstract}

Kata Kunci: Kemampuan Membedakan, Majemuk Setara, Majemuk Bertingkat, Bahasa Indonesia

\section{PENDAHULUAN}

Bahasa memegang peranan penting dalam kehidupan manusia karena bahasa merupakan alat komunikasi manusia yang sangat penting dan menyatu dalam kehidupan berbangsa dan bernegara, sebab tanpa bahasa seluruh interaksi dan aktivitas masyarakat akan menjadi lumpuh. Dengan bahasa memungkinkan semua orang dalam suatu kebudayaan tertentu, atau orang lain yang mempelajari sistem kebudayaan termasuk di dalamnya adalah pendidikan.

Berbicara soal pendidikan berarti ada hubungan dengan pengajaran, karena pengajaran merupakan bagian dari pendidikan dan kegiatan ini mempunyai tujuan yang sejalan dengan tujuan pendidikan nasional. Di dalam sistem pendidikan nasional bahasa Indonesia ditetapkan sebagai mata pelajaran utama yang wajib diajarkan pada semua jenjang pendidikan. Pernyataan di atas mengisyaratkan bahwa di dalam proses pembelajaran bahasa Indonesia di sekolah, guru harus dapat mengembangkan kegiatan belajar kepada siswa agar siswa mampu mengembangkan kemampuan dan keterampilan berbahasa Indonesia baik secara lisan maupun tertulis.

Pembelajaran kebahasaan inklusif dalam pembelajaran keterampilan berbahasa. Dalam hal ini tidak diajarkan secara terpisah sebagai pokok bahasan tersendiri. Pengajaran bahasa Indonesia diarahkan pada aspek keterampilan berbahasa yaitu keterampilan menyimak, berbicara, membaca, dan keterampilan menulis. Proses pembelajaran keterampilan berbahasa, guru harus mencermati secara berkesinambungan kesalahan pemakaian bahasa siswa. Kesalahan-kesalahan tersebut antara lain: pelafalan, pilihan kata, pembentukan kata, pembentukan frasa, kebenaran isi kalimat, penggunaan 
penghubung kalimat, pengembangan paragraf, dan penggunaan ejaan. Salah satu hal yang perlu mendapat perhatian dalam penggunaan kalimat yaitu kalimat majemuk.

Pengajaran kalimat bahasa Indonesia terbagi atas beberapa jenis, yaitu: 1)berdasarkan isinya, kalimat terbagi atas: a)kalimat berita, b)kalimat tanya, dan c)kalimat perintah. 2)Berdasarkan jumlah klausanya kalimat dalam bahasa Indonesia terdiri atas: a)kalimat bersusun dan b)kalimat majemuk. 3)Berdasarkan predikat yang membentuknya kalimat terbagi atas: a)verba dan b)kalimat nominal. 4)Berdasarkan struktur internal klausa utama kalimat terbagi atas: a)kalimat lengkap dan b)kalimat tidak lengkap, dan berdasarkan ada tidaknya perubahan dalam pengucapan kalimat terbagi atas: a)kalimat langsung dan b)kalimat tidak langsung (Putrayasa, 2009).

Pembicaraan mengenai kalimat sangatlah luas. Oleh karena itu peneliti memfokuskan penelitian ini pada kalimat majemuk setara dan kalimat majemuk bertingkat. Menurut Putrayasa (2006:37) kalimat majemuk setara adalah gabungan beberapa kalimat tunggal menjadi sebuah kalimat yang lebih besar, dan tiap-tiap kalimat tunggal yang digabungkan itu tidak kehilangan unsur- unsurnya.

Pada dasarnya kalimat digunakan untuk menyampaikan atau mengutarakan suatu pikiran atau perasaan. Demikian halnya dengan kalimat majemuk setara digunakan dalam kalimat Bahasa Indonesia untuk dapat membedakan arti. Kalimat majemuk setara adalah bila suatu kalimat, baik dengan inti maupun tanpanya, terdiri atas dua bagian inti atau lebih.

Kemampuan menyusun kalimat majemuk setara dan bertingkat secara komunikatif turut menentukan keberhasilan dalam masyarakat. Masyarakat Indonesia pada masa-masa sekarang bahkan yang akan datang membutuhkan tenaga-tenaga kerja yang terampil menggunakan Bahasa Indonesia, surat menyurat, berpidato, dan karang-mengarang (Oka, 1997:53). Relevansi antara kemampuan menyusun kalimat majemuk setara dan bertingkat dengan pembangunan dalam masyarakat itu ditandai dengan adanya bahasa sebagai alat komunikasi dan sekaligus sebagai alat perekat bangsa, sehingga dengan demikian diperlukan adanya keteraturan dalam berbahasa dan ketajaman pemikiran. Kemampuan menyusun kalimat majemuk setara dan bertingkat yang baik selalu didasari oleh pemikiran yang jernih dan mencerminkan ketajaman berpikir. Selain itu, kalimat yang baik sangat memudahkan para penulis dan pembaca untuk mengetahui makna yang dikandungnya.

Dalam kaitan dengan pembelajaran kalimat majemuk setara dan bertingkat ini terdapat kesulitan bagi siswa untuk membedakannya. Kesulitan yang dialami siswa adalah persoalan sintaksis kurang diminati apalagi masalah kalimat majemuk yang bentuknya harus terdiri dari dua kalimat tunggal atau disebut kalimat majemuk setara, begitu pula kesulitan menggabungkan dua kalimat yang bentuknya berbeda karena statusnya sebagai induk kalimat dan anak kalimat dirasa agak menyulitkan.

Sebagaimana hasil observasi yang dilakukan oleh peneliti di SMA Negeri 7 Manado kelas Xc, jug a wawancara yang dilakukan dengan beberapa siswa SMA Negeri 7 Manado kelas Xc, bahwa mereka sering menemui kesulitan untuk membedakan kalimat majemuk setara dengan kalimat majemuk bertingkat. Berdasarkan kenyataan ini maka mendorong peneliti untuk mengangkat permasalahan kemampuan membedakan kalimat majemuk setara dan bertingkat siswa kelas Xc SMA Negeri 7 Manado dalam bentuk penelitian yang berjudul: "Kemampuan Membedakan Kalimat Majemuk Setara dan Kalimat Majemuk Bertingkat Bahasa Indonesia Siswa Kelas Xc SMA Negeri 7 Manado".

\section{METODE}

Metode yang digunakan dalam penelitian ini adalah metode deskriptif kualitatif. Metode deskriptif kualitatif digunakan untuk meneliti pada kondisi objek yang alamiah, di mana peneliti adalah sebagai instrumen kunci (Sugiyono, 2010:15). Sumber data dalam penelitian ini siswa kelas Xc SMA Negeri 7 Manado yang berjumlah 40 orang. Teknik yang digunakan dalam penelitian ini adalah sebagai berikut:

\section{Observasi}

Observasi adalah teknik pengumpulan data yang dilakukan melalui suatu pengamatan, dengan disertai pencatatan-pencatatan terhadap keadaan atau perilaku objek sasaran (Abdurrahmat, 2006:104). 


\section{Wawancara}

Wawancara adalah teknik pengumpulan data dan melalui proses Tanya jawab lisan yang berlangsung satu arah, yang artinya pertanyaan datang dari pihak yang mewawancarai dan jawaban diberikan oleh yang diwawancara (Abdurrahmat, (2006:105). Materi wawancara lebih difokuskan dalam hubungan dengan data penelitian berupa kalimat majemuk setara dan kalimat majemuk bertingkat.

\section{Tes}

Tes dibuat oleh peneliti untuk menjaring data tentang kemampuan membedakan kalimat majemuk setara dan kalimat majemuk bertingkat siswa kelas Xc SMA Negeri 7 Manado. Tes yang diberikan berupa kalimat-kalimat yang terdiri atas kalimat majemuk setara dan kalimat majemuk bertingkat yang susunannya tidak berurutan (acak). Jumlah kalimat 20 buah masing-masing 10 buah kalimat majemuk setara dan 10 buah kalimat majemuk bertingkat. Setiap jawaban yang benar diberi bobot 5 , sehingga jumlah keseluruhan 100. Tes diberikan selama 2 jam pelajaran (08.00-09.30) pada Senin, 8 April 2013. Rumus yang digunakan untuk menganalisis data dalam penelitian ini adalah table persentase dengan rumus sebagai berikut:

$$
\%=\mathrm{n} / \mathrm{N} \times 100
$$

Keterangan: $\mathrm{n}=$ nilai yang diperoleh (nilai siswa)

$$
\mathrm{N} \quad=\quad \text { jumlah seluruh nilai }
$$

(Ali, 1987:184)

Kriteria untuk mengukur keberhasilan siswa sebagai berikut:

$\begin{array}{lll}90 \%-100 \% & = & \text { sangat mampu } \\ 80 \%-89 \%= & \text { mampu } \\ 70 \%-79 \%= & \text { cukup mampu } \\ 0 \%-69 \%= & \text { tidak mampu (Winataputra, 1996) }\end{array}$

\section{HASIL DAN PEMBAHASAN}

Dalam memperoleh data penelitian perihal kemampuan siswa SMA Negeri 7 Manado kelas Xc membedakan kalimat majemuk setara dan kalimat majemuk bertingkat bahasa Indonesia, maka ditempuhlah teknis tes. Tes yang diberikan berjumlah 20 kalimat yang terdiri atas 10 buah kalimat majemuk setara dan 10 buah kalimat majemuk bertingkat yang disusun secara acak. Tes kedua berbentuk mengarang terpimpin yakni membuat masing-masing bentuk kalimat majemuk setara dan kalimat majemuk bertingkat dari 10 buah kata yang disiapkan sehingga jumlah kalimat yang dibuat adalah 20 buah.

Data penelitian ini diperoleh dengan jalan memberikan tes tertulis kepada siswa-siswa kelas Xc SMA Negeri 7 Manado yang berjumlah 40 orang. Tes dilaksanakan di dalam kelas sesuai jadwal mata pelajaran yang ada dan waktu pelaksanaannya selama dua jam pelajaran.

Setelah tes tersebut dikerjakan, oleh siswa-siswa kelas Xc SMA Negeri 7 Manado, hasilnya mereka dikumpul kemudian diberikan lalu diberi skor atau nilai berdasarkan teknik perhitungan secara persentase atas jawaban siswa, baik jawaban yang benar maupun yang salah, baik per orang maupun kelompok.

Untuk mengukur tingkat kemampuan siswa kelas Xc SMA Negeri 7 Manado dalam membedakan kalimat majemuk setara dan kalimat majemuk bertingkat bahasa Indonesia, maka dibuatlah tolok ukur melalui standar rentangan nilai. Hal ini dimaksudkan agar tingkat kemampuan siswa dapat ditentukan. Ametembun (1987:72) mengemukakan tentang tolok ukur melalui standar dengan rentangan nilai tersebut adalah:

$\begin{array}{ll}90 \%-100 \% & \text { Baik Sekali } \\ 80 \%-89 \% & \text { Baik } \\ 70 \%-79 \% & \text { Cukup } \\ 60 \%-69 \% & \text { Kurang } \\ 0 \%-59 \% & \text { Kurang Sekali }\end{array}$


Hasil penelitian ini dinyatakan dalam bentuk angka yang mengukur kemampuan membedakan kalimat majemuk setara dan kalimat majemuk bertingkat siswa kelas XC SMA Negeri 7 Manado, maka digunakanlah tabel persentase sebagaimana dikemukakan oleh Ali (1987:184), sebagai berikut:

$$
\%=\frac{n}{N} \times 100
$$

Keterangan: $\%=$ Persentase

$\begin{array}{lll}\mathrm{n} & = & \text { Nilai yang diperoleh } \\ \mathrm{N} & = & \text { Jumlah seluruh nilai } \\ 100 & = & \text { Bilangan tetap }\end{array}$

Untuk mengetahui kemampuan setiap siswa yang bertindak sebagai informan sebelum dipresentasikan, maka pertama yang harus ditempuh dalam menganalisis data ini adalah membuat tabel tabulasi data informan. Untuk jelasnya dapat dilihat pada tabel berikut.

Tabel 2. Skor Capaian Masing-masing Informan

\begin{tabular}{|c|c|c|c|}
\hline \multirow{2}{*}{$\begin{array}{l}\text { Nomor urut } \\
\text { Informan }\end{array}$} & \multicolumn{2}{|c|}{ Jawaban } & \multirow[t]{2}{*}{ Persentase Benar } \\
\hline & Benar & Salah & \\
\hline 1 & 37 & 3 & 92 \\
\hline 2 & 36 & 4 & 90 \\
\hline 3 & 32 & 8 & 80 \\
\hline 4 & 30 & 10 & 75 \\
\hline 5 & 22 & 18 & 55 \\
\hline 6 & 30 & 5 & 88 \\
\hline 7 & 25 & 15 & 62 \\
\hline 8 & 24 & 16 & 60 \\
\hline 9 & 25 & 15 & 62 \\
\hline 10 & 24 & 16 & 60 \\
\hline 11 & 28 & 17 & 70 \\
\hline 12 & 35 & 5 & 88 \\
\hline 13 & 28 & 12 & 70 \\
\hline 14 & 30 & 10 & 75 \\
\hline 15 & 28 & 12 & 70 \\
\hline 16 & 28 & 12 & 70 \\
\hline 17 & 15 & 25 & 40 \\
\hline 18 & 28 & 12 & 70 \\
\hline 19 & 30 & 10 & 75 \\
\hline 20 & 30 & 10 & 75 \\
\hline 21 & 26 & 14 & 65 \\
\hline 22 & 27 & 13 & 67 \\
\hline 23 & 26 & 14 & 65 \\
\hline 24 & 28 & 12 & 70 \\
\hline 25 & 27 & 13 & 67 \\
\hline 26 & 30 & 10 & 75 \\
\hline 27 & 30 & 10 & 75 \\
\hline 28 & 29 & 11 & 73 \\
\hline 29 & 30 & 10 & 75 \\
\hline
\end{tabular}




\begin{tabular}{|l|l|l|l|}
\hline 30 & 39 & 10 & 75 \\
\hline 31 & 30 & 10 & 75 \\
\hline 32 & 30 & 10 & 75 \\
\hline 33 & 30 & 10 & 65 \\
\hline 34 & 25 & 15 & 62 \\
\hline 35 & 30 & 10 & 75 \\
\hline 36 & 26 & 14 & 65 \\
\hline 37 & 28 & 12 & 70 \\
\hline 38 & 30 & 10 & 75 \\
\hline 39 & 26 & 14 & 65 \\
\hline 40 & 30 & 10 & 75 \\
\hline Jumlah & \multicolumn{2}{|l}{} \\
\hline
\end{tabular}

Hasil di atas belum dapat memberikan gambaran kemampuan siswa, karena itu untuk mendapatkan gambaran jelas tentang kemampuan siswa kelas Xc SMA Negeri 7 Manado dalam membedakan kalimat majemuk setara dan kalimat majemuk bertingkat bahasa Indonesia, maka haruslah dicari persentase dengan rumus yang dikemukakan Ali (1987).

Rumus $\%=\frac{n}{N} \times 100 \%$

Keterangan : $\%=$ persentase

$\mathrm{n}=\quad$ Nilai yang diperoleh

$\mathrm{N}=$ Jumlah seluruh nilai

$\mathrm{n} \quad=\quad 2860$

$\mathrm{N}=4000$

$\%=\frac{2860}{4000} \times 100 \%$

\section{$=70,15 \%$ atau berada pada kategori cukup mampu}

Hasil analisis dimasukkan ke dalam tabel rentang. Nilai yang dilambangkan dengan sistem turus. Sistem turus tersebut dapat dilihat pada tabel berikut.

Tabel 4. Tabel Rentang Nilai dalam Turus

\begin{tabular}{|c|c|c|c|}
\hline $\begin{array}{l}\text { Rentang } \\
\text { Kriteria }\end{array}$ & Turus & Siswa & Jumlah \\
\hline $90-100 \%$ & // & 1 dan 2 & 2 \\
\hline $80-89 \%$ & /I & $3,6,12$ & 3 \\
\hline $70-79 \%$ & /II/ III/ III/ III/ I/ & $\begin{array}{l}4,11,13,14,15,16, \\
19,20,24,26,27,28, \\
29,30,31,32,33,35, \\
38,40\end{array}$ & 22 \\
\hline $60-69 \%$ & $|I I I| I / I / \mid$ & $\begin{array}{l}7,8,9,10,21,22,23 \\
25,34,36,39\end{array}$ & 11 \\
\hline $0-59 \%$ & $/ 1$ & 5,27 & 2 \\
\hline
\end{tabular}

Berdasarkan hasil perolehan siswa kelas XC SMA Negeri 7 Manado melalui tes maka diperoleh kesimpulan sebagai berikut:

1. Siswa yang mendapat nilai di atas $90 \%-100 \%$ berjumlah 2 orang siswa.

2. Siswa yang mendapat nilai di atas $80 \%-89 \%$ berjumlah 3 orang siswa.

3. Siswa yang mendapat nilai di atas $70 \%-79 \%$ berjumlah 22 orang siswa. 
4. Siswa yang mendapat nilai di atas $60 \%-69 \%$ berjumlah 13 orang siswa.

5. Siswa yang mendapat nilai di atas $0 \%-59 \%$ berjumlah 2 orang siswa.

Memperhatikan Tabel 3 dapatlah dikatakan bahwa 3 orang siswa berada pada rentang nilai persentase $80-89 \%$, hasil ini menunjukkan bahwa ketiga siswa tersebut dapat digolongkan memiliki kategori baik, 22 siswa berada pada rentang nilai persentase 70-79\%. Hasil ini menunjukkan bahwa 22 siswa tersebut tergolong cukup mampu. Siswa yang memperoleh nilai pada rentang 60-69\% berjumlah 13 siswa, hasil ini menunjukkan bahwa 13 siswa tersebut berada pada kriteria kurang. Dari siswa yang memperoleh nilai pada rentang 50-59\% berjumlah 2 orang. Hasil ini menunjukkan 2 orang siswa berada pada kriteria kurang sekali.

\section{KESIMPULAN}

Berdasarkan uraian yang telah disajikan di depan memperlihatkan bahwa kemampuan siswa kelas Xc SMA Negeri 7 Manado dalam membedakan kalimat majemuk setara dan kalimat majemuk bertingkat bahasa Indonesia berada pada tingkat capaian 70,15\% atau dalam rentang nilai $70-79 \%$ yang dapat dikategorikan pada kemampuan cukup. Dengan demikian maka guru bahasa Indonesia itu harus lebih aktif serta memotivasi siswa agar tingkat kemampuan siswa membedakan kalimat majemuk setara dan bertingkat bahasa Indonesia akan meningkat. 


\section{DAFTAR PUSTAKA}

Ali, Muhamad. 1987. Penelitian Kependidikan Prosedur dan Strategi. Bandung: Angkasa. Alwi, H. dkk. 1996. Tata Bahasa Baku Bahasa Indonesia. Jakarta: Balai Pustaka.

Akhaidah. 1984. Pengajaran Bahasa Indonesia. Jakarta: Rineka Cipta.

Arikunto, S. 2006. Prosedur Penelitian Suatu Pendekatan Praktik. Jakarta: Rineka Cipta.

Abdurrahmat, H. 2006. Metode Penelitian dan Teknik Penyusunan Skripsi. Jakarta: Rineka Cipta.

Chaer, Abdul. 1993. Tata Bahasa Praktis Bahasa Indonesia. Jakarta: Barata Karya Aksara.

Keraf, Gorys. 1987. Tata Bahasa Indonesia. Nusa Indah: Ende Flores.

Putrayasa, Ida Bagus. 2006. Tata Kalimat Bahasa Indonesia. Bandung: PT Refika

Aditama. Putrayasa, Ida Bagus. 2009. Jenis Kalimat Dalam Bahasa Indonesia. Bandung: PT Refika Aditama.

Putrayasa, Ida Bagus. 2006. Analisis Kalimat. Bandung: PT Refika. Ramlan, M. 2015. Sintaksis. Yogyakarta: UP. Karyano.

Surakhmad. 1987. Pengantar Penelitian Ilmiah Dasar, Metode dan Teknik. Sugiyono. 2010. Metode Penelitian Kuantitatif Kualitatif dan R\&D. Alfabet. Sugondo. 1999. Berbahasa Indonesia Dengan Benar. Jakarta: PT. Surabaya. Tarigan, H.G. 1984. Pengajaran Sintaksis. Bandung: Angkasa.

Winataputra, S. dkk. 1996/1997. Belajar dan Pembelajaran Depdikbud PDM Proyek Penataran Guru Setara D-III. 